\title{
Analysis of Discussion Board Interaction in an Online Peer Mentoring Site
}

\author{
Regina Ruane, Ph.D. and Vera J. Lee, Ed.D. \\ Drexel University
}

\begin{abstract}
This study uses Critical Discourse Analysis and Social Network Analysis to examine an online peer mentoring site created to unite first-year and third-year preservice teachers enrolled in an undergraduate teacher education program. The peer mentoring site was developed to provide both first-year preservice teachers and more experienced peers the opportunity to discuss, share, and learn both from and with one another. The study demonstrated that the online peer mentoring site supported valuable interactions and professional communications among firstyear and third-year students. In particular, the preservice teachers engaged with one another to share their experiences and learning as they prepared to be teachers. This study has implications for the field of undergraduate education in its demonstration that an online peer mentoring site can allow for the cultivation of learning, ideas and knowledge exchange, and support of students learning in informal environments. This research also has implications for future research to determine how different populations of students use an online peer mentoring site to interact with their peers and the outcomes that emerge. Such data could inform future development of peer mentoring sites and similar learning spaces.
\end{abstract}

Keywords: peer-mentoring, computer-supported collaborative learning, online learning, higher education 
Analysis of Discussion Board Interaction in an Online Peer Mentoring Site

\section{Introduction}

Rapid advances in computer and communication technologies in recent decades have dramatically changed the ways students learn (Stahl, Koschmann, \& Suthers, 2013). In online courses, instructors promote collaborative learning to engage students in active construction of knowledge through exploration of ideas in peer-to-peer communication (Haythornthwaite \& Andrews, 2011). Moreover, technology provides social affordances in online learning that include ways of communicating with others, being visible in the online context, viewing and using data and information, and obtaining other resources (Haythornthwaite \& Andrews, 2011). While there are many benefits to online learning, individuals in new, computer-supported learning environments face an overwhelming array of new challenges, which include adjusting to new media, new rules of behavior, and new course materials and classmates (Haythornthwaite, 2002). These initial challenges can be expected to fade with increased familiarity with the online learning platform, but the initial adjustment period can create a serious impediment for students taking online courses for the first time (Haythornthwaite, 2002).

Pedagogical theory and technological advances have opened opportunities to design innovative and powerful environments to support student learning (Barab, 2003). The growing uses of Internet-based platforms affect where, what, and from whom we learn, raising challenges for the future of educational practice (Haythornthwaite, 2012). In the field of teacher education, communities of practice have provided support for preservice teacher education students during and after their training (Barab \& Duffy, 2000). For more than a decade, peer mentoring has been offered in online settings with mentoring defined as an expert (or mentor) supporting or advising a novice (or mentee) (Dennen, 2004). Few research studies have explored the ways that students are using peer mentoring sites and the interactions that occur among students in these settings. Participative, peer-based approaches affect teaching and learning and the development of curricula in many ways (Paulin \& Haythornthwaite, 2016). Who takes and/or maintains authority in an online community has been the subject of much research (Benkler, 2006, Paulin \& Haythornthwaite, 2016; Rheingold, 2000, 2007).

The purpose of this study was to better understand the ways in which preservice teachers were using an online peer mentoring site designed to provide a forum for interaction through threaded discussions among first-year and third-year students enrolled in an online undergraduate teacher education program. Specifically, the study investigated the social language that developed among the preservice teachers, the ways that the students used the site to support their development as teachers, as well as the effectiveness of the site for the preservice teachers as a forum for the exchange of ideas and learning. According to Feenberg and Bakardjieva (2004), it is extremely important to continue systematic research efforts among online groups to "identify, describe, and understand the specific forms of social life within computer-supported environments and the related benefits, drawbacks, and consequences for participants, culture, and society” (p. 41). Examining the students' social and communication behaviors in the peer mentoring site offers a deeper understanding of the ways in which online platforms could be used to effectively engage and support students in their learning and achievement. The study explored the following research questions: (a) How did preservice teachers use the peer mentoring site? (b) What social language developed among them? and (c) Was the peer mentoring successful in providing new and more experienced preservice teachers 
with a forum for interaction to further develop, ask questions, and share what they have learned?

\section{Theoretical Framework}

The theories guiding this study include Critical Discourse Analysis and Social Network Analysis. While Social Network Analysis offers structural information about the composition of interactions and relationships established by the participants in an online classroom (Scott, Carrington, \& Peter, 2011), Critical Discourse Analysis analyzes social language (Gee, 2011) in the peer mentoring site to better understand the ways in which participants are using the site for individual and common purposes. This theoretical background provides a conceptual view for this study of peer mentoring interactions in a situated online context designed to bring a group of preservice teachers together.

\section{Critical Discourse Analysis}

Critical Discourse Analysis refers to theories and methods used in educational research that emerged from various disciplines such as linguistics, anthropology, communications, and cultural studies (Rogers, 2011). Critical Discourse Analysis, or CDA, offers a useful way of analyzing texts, discourse, and other social interactions across different contexts and at different times (p. 1). There are diverse approaches and ideologies about CDA, but one commonality between them all is the notion that "language is a social practice and because not all social practices are created and treated equally, all analyses of language are inherently critical” (p. 2). This position is often connected to the work of Gee (2011) who argued that language is inherently political, and therefore any analysis of language will necessitate a critical approach to understanding how language "uncovers different ways of saying things, doing things, and being things in the world” (p. 9). By closely examining language in written or spoken text, it offers opportunities to learn how individuals use language to make sense of an activity they are engaged in, what identities they adopt within certain contexts, or how they use it to build relationships with other people (p. 18-19).

Furthermore, Gee (1989) defines discourse as "ways of being in the world" (p. 6), and makes a distinction between discourse with a capital D and discourse with a lower case d. Discourse with a capital D refers to the identity or social role an individual plays in a particular setting and manners of speech, writing, and behaviors are "socially situated" and appropriate for that context (p. 6). It suggests the myriad purposes and intentions for which individuals will use language to act upon and participate in the world (Rogers, 2011, p. 7). Discourse with a lower case "d" refers to actual written or spoken text or the "grammar of what is said or written" (Rogers, 2011, p. 7). It pertains to the functional use of language (p. 7). Taken together, Gee's (1989) construction of the two types of discourse informs his approach to analyzing language patterns.

\section{Social Network Analysis}

Social network analysis provides a vocabulary and set of techniques for understanding interpersonal interactions in communities, offline or online (Scott, Carrington, \& Peter, 2011). Social network analysts study relations or ties, either work ties or friendship ties, in order to understand the ways in which individuals exchange resources and how these exchanges create 
connectivity among all members. Increasingly, social network approaches have shown how online interaction transforms, extends, and impacts learning (Rainie \& Wellman, 2012).

Social network analysis is based on the premise that social life is created primarily by relations and the patterns formed by these relations (Marin \& Wellman, 2010). Relationships combine to form ties and patterns to reveal social networks and subnetworks (Haythornthwaite, 2005). Social network analysis (Scott et al., 2011) is suited to analyzing online learning spaces and mentoring sites because of its focus on understanding the structure and composition of peer interactions and relationships. Information regarding the ties that students are maintaining show the patterns of interaction, specifically who turns to whom for support, how frequently, and how information travels among the participants in the peer mentoring site.

\section{Literature Review}

To build the contextual framework, research regarding online learning, peer mentoring, and communities of practice literature are included to demonstrate pertinent aspects relevant to this study and its locale. The online and peer mentoring literature provides information regarding student interactions in such settings. Communities of practice literature provides background and conceptualization of such systems, and the ways in which students can learn from one another.

\section{Online Learning}

The successful development of educational programs and courses in the online format has provided momentum and "new paradigms of learning that accompany the continuing expansion of the Internet, online learning, and online learning relationships" (Haythornthwaite \& Andrews, 2011, p. 2). The great strides in online course development, teaching, and evaluation have contributed to the academic success of students, instructors, and programs. In online learning environments, interactions in discussion forums can embody highly complex processes between participants involving questions, explorations of information, construction of possible solutions, and a resolution of a problem or question or interactions like providing feedback, making connections, or reflecting on others' opinions (Meyer, 2006). Nicholson and Bond's (2003) analysis of interaction in online field-based education courses indicated that preservice students used the Discussion Boards as a place for professional support and community. Transcripts generated around online courses in discussion boards, blogs, wikis, and Twitter open a new window through which to see teaching and learning that can then influence the design and use of learning networks (Haythornthwaite, 2013). Learning networks can be analyzed from the perspective of informing future designs of such environments (Goodyear \& Carvalho, 2014).

\section{Peer Mentoring}

Peer mentoring programs provide an avenue for new students to be supported by more experienced mentors and make social connections with other new students (Glaser, Hall, \& Halperin, 2006). Along with face-to-face settings, computer-supported learning environments offer the opportunity for mentors and students who are not co-located to engage in mentoring experiences (Dennen, 2004). Dennen (2004) suggests that research in online learning has been robust, and technology holds great promise as a mediator and provider of mentoring opportunities. Hayward et al. (2001) found that mentors and mentees have heightened reflective 
experiences in a computer-supported collaborative setting. Mentoring programs have a positive effect on new students entering higher education as peers are often considered the most powerful influence in undergraduate education, (Ender \& Newton, 2000).

\section{Communities of Practice}

Communities of practice are emerging, evolving, and self-reproducing entities, which are distinct from and often extend beyond organizational structures, and have their own methods of organization, norms of behavior, communication channels, and history (Barab \& Duffy, 2000). A community of practice is an entity that has structure and identity that consists of, but is different from, its individual members (Lave \& Wenger, 1991). Community identity, according to Barab, Barnett, and Squire (2002), can be thought of as a classroom culture, which is constantly transforming as new members contribute, support, and eventually integrate. Even though new members are changing the culture, the group will have a common history. History, according to Barab et al. (2002), provides continuity and a stable structure for student interaction so that newcomers to a community are not left to create boundary structures each time.

Communities of practice provide students with opportunities to become both active and purposeful participants in quality educational experiences aiding in the enhancement of learning outcomes (Cross, 1999) and the creation of networks for learning (Goodyear \& Carvalho, 2014). Communities of practice are critical for knowledge-building and knowledge-building routines and provide collaborative social opportunities that allow individuals the freedom to think flexibly and experience different forms of support (Schlager \& Fusco, 2003). As Barab et al. (2002) found among the preservice teachers, learning in these settings can be a complex process involving the overlap of meaning, practice, experience, identity, and community, where newcomers evolve, grow, and learn from the more experienced members. The openness of the Web changes how, where, and when we learn, creating environments, where learner-participants create the content of their learning (Paulin \& Haythornthwaite, 2016). These settings open a new window that can then influence the design and use of learning networks (Haythornthwaite, 2013) and the way in which communities of practice and mentoring relationships can develop without time and location constraints.

Lave and Wenger (1991) categorize learning in certain forms as social co-participation, where social engagements provide the context for learning to occur. Learners acquire the skills to perform by engaging in an enculturation process (under the attenuated conditions of legitimate peripheral participation). Legitimate peripheral participation offers a way to speak about the inevitability of learner participation in "communities of practitioners and...the mastery of knowledge and skill require newcomers to move toward full participation in the sociocultural practices of a community” (p. 29). Learning is a practice, and engaging with others helps form the families of practice that allow the ideas to take hold in peoples' repertoires (Lave \& Wenger, 1991). Coordinating and communicating in endeavors with others involves adjustments to stretch common understanding to fit with new perspectives of their shared learning (Rogoff et al., 1995).

Lave and Wenger (1991) found that in situated environments where novice learners moved through phases to become experts, the learners had embraced and experienced the rich 
significance of learning in these contexts. Similarly, with the situated aspect of the online learning environment, situated learning theory provides a lens through which to analyze the development of online learners as they move from novice to expert in a peer mentoring setting. According to Wenger (2009), when technology enables practice, participants are offered a unique perspective because they are not defined by place or personal characteristics, but by people's potential to learn together. The learning comes through interaction, where participants continuously reinvent themselves, thereby expanding the understanding of their domain (Wenger, 2009).

Situated learning acts as a bridge between the cognitive processes of learning and social practice, where learning to become a participant in a community involves learning how to talk and act in the manner of the other participants (Lave and Wenger, 1991). Scheckler and Barab (2009) describe learning as a process of inquiry and as a process of doubt, which is followed by the search for solutions to resolve the doubt in a cultural-historical context (situation), which transforms the situation. Learning is done collegially and socially through interactions with others and is mediated by the differences of perspective among co-participants (Lave and Wenger, 1991). Lave and Wenger (1991) believe that meaning, understanding, and learning are all contained within active contexts, not self-contained structures with thinking and interpersonal communication as joint endeavors (Sfard, 2008).

\section{Methodology}

The purpose of this study is to understand the ways that students interacted in an online peer mentoring site situated in an undergraduate teacher education program, the social language that developed, and what these interactions indicate. To pursue this research, a peer mentoring site was selected that provided a purposeful and relevant sampling. The students who participated in the peer mentoring site were completing co-requisite seminar courses, either at the junior level or at the freshmen level. The Critical Discourse Analysis (CDA) approach provided a micro-level analysis of the participants' Discussion Board posts to determine how the students developed a discourse for interaction and relationship building with one another (Gee, 2005). Social Network Analysis provided a macro-level analysis of the student interaction in the peer mentoring site. The purpose of this analysis is to provide a way to describe the nuances of online interactions and connectivity as it considers social structure to be the patterned organization of network members and their relationships (Wellman, 1997). Information regarding the ties that students are maintaining will show the patterns of interactions, specifically who turns to whom for support, how frequently, and how information travels among the participants.

\section{Research Site}

This research was conducted at a private university located in the northeastern region of the United States. This university began offering online education programs in 1996. Approximately 26 undergraduate/graduate degree and certification programs are offered at this university using fully online or hybrid models. The peer mentoring site that was selected for this study connected students completing two courses, the freshmen pedagogy seminar and the junior pedagogy seminar. Both courses are required for completing the baccalaureate degree in teacher education. The peer mentoring site was offered completely online from January to April of 2009. While the data was collected seven years ago, and there may be potential issues with the age of 
the data, the findings from this study remain relevant and add to the field's understanding of the efficacy of fully online peer mentoring sites as viable spaces for the development of preservice teachers.

The peer mentoring site allows new and more experienced students the opportunity to engage in discussion and problem-solving situations. The mentoring site discussions were scheduled for seven of the ten weeks of the courses with topics changing for each increment in the Blackboard ${ }^{\mathrm{TM}}$ online learning platform. Blackboard offers online learning environments with flexible delivery options to deliver accessibility for students and faculty to improve engagement and retention. Each discussion began on a Tuesday and continued through the following Monday. The participants in each peer mentoring site were free to re-visit and re-post to previous threads even if a subsequent week's discussion had already commenced. The discussions began with questions posed by the facilitator. Each student was requested to post two to three times during the weekly discussions. The moderating facilitators made no further attempt to define the student participation on the discussion board. Mentoring participation totaled fifteen (15) points out of one hundred (100) for each seminar course, respectively. If the students posted the minimum number of times as requested by the facilitators, they were deemed to have earned the fifteen (15) points for participation. Points were awarded to the students for participation in the discussion board, and not awarded based on frequency of postings.

\section{Participants}

The overall number of participants in the study included forty-six pre-service teachers (see Table 1). Two instructors and the director of the program in which the students were enrolled oversaw the peer mentoring site. This paper focuses specifically on the interactions of six (6) of the forty-six (46) preservice teachers in the peer mentoring site. Since the CDA method involved a rigorous in-depth approach to analyzing data, we decided to select a representative sample of six students and applied the CDA to analyze their interactions on the Discussion Board. The criteria for selecting the six students included equal representation of first-year and third-year students providing both novice and more experienced or expert perspectives in this sampling. The third-year students served as the mentors and the first-year students were the mentees. The selection criteria also included preservice teachers who were highly active and involved in the peer mentoring site and those who were legitimate peripheral participants (Lave and Wenger, 1991), i.e. preservice teachers who were new to the site and demonstrated observational tendencies with fewer written interactions. In addition, the social network analysis provided a macro-level approach to the analysis of the interactions of the selected participants in the peer mentoring site. This approach was used to provide a view of the interaction patterns of all participants in the site, while offering another way to illustrate the activity level of the 6 students in the peer mentoring site.

Table 1 provides information about the six (6) students selected. All students enrolled in the site from which the subset for this study was selected were female. While the program director (Ruane, 2012) was one of the facilitators of the peer mentoring site, the focus of the discussion will be on the interactions between the student participants in the course. 
Table 1

Participant Information

\begin{tabular}{lcccc}
\hline Participants & $\begin{array}{l}\text { Level in the } \\
\text { Program }\end{array}$ & Gender & Certification Area & $\begin{array}{l}\text { Participated in a } \\
\text { previous peer } \\
\text { mentoring site }\end{array}$ \\
Participant A & Junior & Female & Elementary & No \\
Participant B & Junior & Female & Elementary & No \\
Participant C & Freshman & Female & Elementary & No \\
Participant D & Freshman & Female & Elementary & Yes \\
Participant E & Freshman & Female & Elementary & No \\
Participant F & Junior & Female & Elementary & No \\
\hline
\end{tabular}

\section{Data Source}

This research came from a larger study, which focused on the interaction patterns of students in the peer mentoring sites from 2008 to 2012 (Ruane, 2012). The research findings in this article present a smaller, but significant piece of the larger study. The data for this study was collected by obtaining the text from threaded discussions of the peer mentoring site in Blackboard $^{\mathrm{TM}}$ from January to April of 2009. In order to ensure the anonymity and objectivity of the data obtained from the online discussions, the first author de-identified all of the postings.

\section{Data Analysis}

The discussion board posts and exchanges of six preservice teachers were analyzed utilizing Gee's (2001) CDA process. Gee’s (2011) framework is useful for studying how people use language, which he referred to as the "seven building tasks of language" (p. 32). For the purposes of the present study, only four of the building tasks were selected to make sense of the data: significance, practices, identities, and relationships. Significance refers to how an individual uses language to place more or less importance on certain ideas or things (Gee, 2011). Practices or activities refer to the ways in which an individual uses language to gain recognition for engaging in culturally specific practices (Gee, 2011). The concept of identities pertains to the idea that an individual will use language to enact one's identity or attribute an identity onto someone else (Gee, 2011). Lastly, the concept of relationships refers to the ways in which an individual will use language to build relationships with other people. The discourse analysis questions developed by Gee (2011) were used to analyze how the student participants enacted these tasks (see Table 2). In addition, social network analysis of the student interactions was also considered to provide a visualization of the interaction patterns of the participating students across the peer mentoring site. A matrix was created of the student interactions to prepare the data for the social network analysis. The matrix was comprised of all the directed interactions, i.e. those interactions addressing a particular recipient, in the peer mentoring site. UCINet, a 
Windows program for visualizing social network data, was used to view the student interactions for the duration of the peer mentoring site in sociogram form.

Table 2

Gee’s (2011) Discourse Analysis Questions

\begin{tabular}{ll}
\hline Significance & $\begin{array}{l}\text { How is the piece of language being used to make certain things } \\
\text { significant or not and in what ways? }\end{array}$ \\
Practices (Activities) & $\begin{array}{l}\text { What practice (activity) or practices (activities) is this piece of } \\
\text { language being used to enact? }\end{array}$ \\
Identities & What identity or identities is this piece of language being used to \\
enact? What identity or identities is this piece of language \\
attributing to others and how does this help the speaker or writer \\
enact his or her own identity? \\
What sort of relationship or relationships is this piece of \\
language seeking to enact with others (present or not)?
\end{tabular}

Gee's questions from his "building blocks of language" were employed to examine the Discussion Board exchanges of the six preservice teachers. The next section will discuss the findings of the CDA and social network analysis.

\section{Results}

In this section, we report the results of the social network analysis and our application of Gee's (2011) CDA approach to the Discussion Board posts of the students in the peer mentoring site to uncover certain topics or issues that were significant for them, the types of activities enacted by the students, examples of identities taken up by specific learners within the site, and how relationships were meaningfully built among them. The findings are organized around Gee's (2011) “tools of inquiry”: significance, practices, identities, and relationships and the social network analysis.

\section{Significance}

During week two of the course, the preservice teachers placed great significance (Gee, 2011) on the topic of gifted or advanced students in a discussion about differentiated or individualized instruction. The students responded to a question posed by one of the instructors, "I have a question about the terminology we educators use. Should we differentiate lesson plans for different students or should we individualize for all students?” (Program Director, January 23, 2009). In the following exchange, the preservice teachers described how gifted or advanced students often help students who struggle. They suggested that it is important for teachers to remember that gifted or advanced students have learning needs that need to be addressed:

For me, individualizing is a better term...because we can't have a specific lesson plan for each individual child (Participant C, January 23, 2009). 
Analysis of Discussion Board Interaction in an Online Peer Mentoring Site

I think we sometimes forget about the children that are advanced and maybe as teachers we can offer them incentives to help those children that need more help (Participant E, January 27, 2009).

The children that are advanced can help with those that struggle, but teachers should not rely on them either. Is that fair to the high achieving student? The high achievers least restrictive environment needs to be considered as well (Participant D, January 27, 2009).

Participant D, I agree with you that teachers shouldn't rely on their gifted students. My daughter who has Asperger Syndrome began to read when she was 3 years old, when she was 5 and in Kindergarten. I can remember being so upset with her teacher because she would have (daughter's name) read things to the other students (Participant F, January 28, 2009).

I think that when one is differentiating a lesson they are just making it more accessible to the different levels of learners as a whole class...individualizing is when the teacher pulls a child separately to work on their specific needs (Participant B, January 24, 2009)

The students in this exchange used specific language that is easily recognized by members of the larger education community to consider the fairness of using advanced or gifted students to support struggling students in the classroom. They also invoked a social language (Gee, 2011, p. 46) and terminologies that are appropriate for discussing students who have potential learning disabilities such as an IEP (Individualized Education Plan), and a resource room (a popular pullout model for students needing specialized support). By placing significance on the topic of advanced students opposed to learners with learning disabilities, the students are having a broader conversation (Gee, 2011) about how the needs of gifted students are not being met in schools. This discussion is important because it echoes concerns in the field that gifted students are not challenged or supported in the same ways that struggling students are in the classroom (Winebrenner, 2000). Furthermore, the preservice teachers adopted the discourse (Gee, 2011) of their profession as seen in Participant F's use of field-specific language and terms such as “differentiating," "accessible," and "individualizing” that represented her membership and identification with K-12 educators.

\section{Practices (Activities)}

In the peer mentoring site, the preservice teachers formed practices around pragmatic issues in teaching. The preservice teachers engaged in activities on the site to support one another or obtain practical information regarding teaching or their preparations i.e. licensures and exams that are required to become a teacher. They also solicited information about certification requirements, classroom management techniques, and instructional strategies. As the following quote from Participant B demonstrates, the students asked for and provided information about teacher certification requirements in other states.

I live in NY and plan to teach here so I understand your concern. Since [the university] is in PA, I have to become certified as a PA teacher first and then apply to NY under reciprocity agreement. I then get an initial certificate in NY and have two years to take 
NY tests (Participant B, January 14, 2009)

One important activity the preservice teachers engaged in on the peer mentoring site was to request and provide practical information about the Praxis (teaching licensure) exam and advice about preparing for the exam. Participant E's questions illustrated the types of questions the participants asked from students who had already taken their Praxis tests and were undergoing the certification process in their states.

Is the test long? Are the study/prep guides relevant to the tests? I live in Alpha, NJ and a matter of 5 miles from Pennsylvania. I am debating whether to get my Pennsylvania certificate or New Jersey. Is one state better than the other? (Participant E, January 13, 2009)

The social language enacted in Participants B's and E's posts exhibited their understanding of the credentialing steps that are necessary in order to become a certified teacher in a particular state, but it also revealed important decisions they needed to make about the pros and cons of seeking licensure in one state versus another. For instance, Participant E's question "Is one state better than the other?" underscores the gravity of this decision, and she solicited the advice of her classmates who could provide critical insights into the advantages and disadvantages of being licensed in Pennsylvania versus New Jersey, a decision that will determine where she can teach.

A vital skill preservice teachers need to acquire to be effective educators is classroom management. During week four of the term, the students discussed effective and ineffective classroom management skills that they observed during their fieldwork experiences. In the following post, Participant A shared a story about a teacher who exhibited excellent management skills by saying very little to her students, getting their attention without demanding it, and without embarrassing her students in front of the class.

The teacher I observed last quarter would only say the words "So sad" and the students usually would stop what they are doing and begin to pay attention. It was a easy way to get the students attention without having to pay a lot of attention to what they were doing or embarrass them in front of the class. The teacher had great classroom management skills and I hope to find that someday (Participant A, February 15, 2009) .

According to Meyer (2006), interactions in online courses can serve a range of purposes from providing feedback to pondering more complex opinions shared by other students. In these examples, the preservice teachers demonstrated their flexible use of the peer mentoring site from obtaining simple information about taking the Praxis exam or credentialing questions to engaging in more complex discussions about what effective classroom management looks like and the type of disciplinarian they hoped to become. The social language enacted in these posts represented the simple to highly complex activities (Romiszowski \& Ravitz, 1997) that occurred in the peer mentoring site, from basic information giving or gathering to negotiating beliefs about classroom management styles and practices. The interactions demonstrate the differences in experience levels among the first-year and third-year preservice teachers. Despite the different levels, the interactions provide positive benefits to both levels of students. 


\section{Identities}

According to Gee (2011), individuals use language to assume or construct a particular identity or role (p. 18). The interactions of the selected preservice teachers showed that identities (Gee, 2011) were formed around the knowledge and experiences they have had in the field. This is particularly evident from the interactions Participant $\mathrm{F}$ had with the other learners on the peer mentoring site. Participant $\mathrm{F}$ assumed the role of a more experienced preservice teacher. Her posts described her experiences as an upper-level student, an instructional assistant, and a parent. She shared the knowledge and experience she gained with her classmates. In the following post, Participant F wrote about the important experience she gained from her work as an instructional assistant.

I actually did more actual 'teaching' as an instructional assistant because at one point I was a one-on-one with a child with special needs and one year I was with six kids in the same class. Oddly enough, the one year I was with the one student, the parents would communicate more with me than with the teacher which was an idea I was not comfortable with. In that case, the regular education teacher did not like having special needs kids so I felt the need to be the advocate for the little boy (Participant F, January 15, 2009).

This post portrayed Participant F's growing confidence in her development as a teacher. The actions of the parents in the classroom where Participant F worked as an Instructional Assistant echo this confidence with their preference to speak to her about concerns, rather than with the head teacher. The parents perceived Participant $\mathrm{F}$ as advocating for and caring about the needs of their children, more so than the veteran teacher in the classroom. They approached her and saw her as the "head teacher" even though she was the instructional assistant.

Furthermore, in her Discussion Board posts, Participant F often exuded confidence in communicating what she learned from the time she spent in various classrooms, and affirmed her role as that of the "veteran preservice teacher" in the peer mentoring site: "This is a great idea. I never see this done in the older grades. The kids do get a recess break...but they aren't allowed out of their seats to move around so it doesn't help them” (February 2, 2009). This post was part of a larger conversation regarding classroom management and as well as a response to another preservice teacher's post who described a teacher who permitted students to stand up and stretch after sitting at their desks for long periods of time. Participant F's response, "I never see this done in older grades," indicates that she has seen this method used frequently with younger students presumably through her work and experience as an Instructional Assistant. Throughout the term, Participant F's posts also showed a genuine interest in the experiences of others. She is a very active participant in the peer mentoring site, responding to her peers' posts with questions for more information, and providing suggestions and advice based on her experiences.

Participant F's experience, knowledge, and activity in the peer mentoring site propelled her to the forefront of many discussions. Other participants affirmed her identity as the "veteran preservice teacher” as well: “I loved your post. Isn't it amazing how the little boy C could type so fast? The raised bump paper story is awesome also. You have a great base of experience for your life as a teacher” (January 25, 2009). Participant B, another third-year preservice teacher, 
was responding to a post written by Participant $\mathrm{F}$ in which she shared an experience from an elementary school resource room where she worked that involved a fourth grade student who was not able to write in cursive and had difficulty printing. In her post, she stated that the head teacher "suggested that he type on the computer for his written assignments and you wouldn't believe how fast he could type” (January 22, 2009).

The veteran role and identity that Participant $\mathrm{F}$ assumed in the peer mentoring site contrasted with the identities of the other preservice teachers. Considering Participant F's gregarious nature and multifaceted experience with regard to teaching, she quickly became the central figure in this site. In contrast, Participant D, a first-year student, was not a very active participant, posting only a few times on the Discussion Board for weeks 2, 3, and 4. The following post from Participant D illustrated her level of interaction in the peer mentoring site: "I have really been enjoying these posts. I have not posted a thread because what I have read has answered a lot of my questions. Thanks for all the great input everyone has shared" (Participant D, January 26, 2009). Participant D's brief statement in this post exhibited her identity as someone who is actively reading what other students have written, but she did not engage or participate actively on the online site in the way that Participant F had. Participant D viewed herself as learning "from” her classmates, as opposed to offering advice and ideas "to" others.

\section{Relationships}

In the peer mentoring site, the preservice teachers formed relationships (Gee, 2005, p. 31) around their passion for teaching students. According to Gee (2011), individuals use language to build and sustain relationships of all kinds (p. 31). The preservice teachers' posts described their own experiences in overcoming hurdles, fears, or anxieties related to the teaching profession. In the following example, Participant $\mathrm{C}$ solicited advice from her classmates about teaching students for the first time: "Was it hard your first time to get up in front of the students and start teaching them?” (Participant C, January 14, 2009). The other preservice teachers rallied around her, providing encouragement and reassurance. Participant B responded by stating, "The first time I taught a lesson in front of 19 kindergarteners I thought I was going to pass out. I was extremely nervous. Now I am much more comfortable” (Participant B, January 16, 2009). As a result of the outpouring of support and guidance she received from her classmates, Participant $\mathrm{C}$ responded:

Thank you all for the great advice, if I stay focused on why I am there it will really help me... These are perfect little angels relying on me to teach them and to me that is really scary, but within time I will learn. (Participant C, January 18, 2009)

As a first-year student in a teacher education program, Participant $\mathrm{C}$ offered an honest portrayal of her struggles in confronting some of the "unknowns" ahead of her as a preservice teacher. The social language taken up in this exchange between Participant $\mathrm{C}$ and her classmates revealed the level of comfort she had in the peer mentoring site, and the positive relationships she built with the other students to honestly reveal her concerns and questions about teaching children for the first time. Participant B's response showed empathy and support for Participant C as she tried to ease her fears by recalling the first time she taught kindergarten students.

The "socially situated activity" (Gee, 2011, p. 60) reflects one of the purposes of the peer 
mentoring site: to provide opportunities for first- and third-year students to exchange ideas and interact in meaningful ways. The site also allowed students to form meaningful relationships in a situated learning environment (Lave \& Wenger, 1991) where first-year preservice teachers can openly share their personal struggles about the teaching profession with their classmates. Moreover, the discourse that is taken up in this excerpt reveals emotionally laden language that underscores the heavy responsibility that Participant $\mathrm{C}$ felt about ensuring that her future students received the education that they need and deserve. Her use of the descriptor "perfect little angels" highlights the idea that young children are not responsible for their education; rather, teachers ultimately hold that responsibility.

In addition to the analysis of the interactions of the six participants using Gee's CDA approach, social network analysis was also used to analyze social interaction patterns from a macro perspective in the context of their activity among all the students in the peer mentoring site. NetDraw, a function of UCINet, was used to display the directed interactions of the students enrolled in the peer mentoring site (Borgatti, Everett, and Freeman, 2002). Figure 1 provides a sociogram drawn using NetDraw to display the directed interactions of all of the students enrolled in the Fall 2008 peer mentoring site. This figure demonstrates the established ties among the first-year and third-year participants in this setting.

This analysis demonstrates that the selected students (Participants A-F) were active members of this site and had interactions with other participants. In Figure 1, Participant A is represented as 8, Participant B as 3, Participant C as 19, Participant D as 18, Participant E as 46, and Participant $\mathrm{F}$ as 7 . The sociogram shows that Participants A, E, and B were the most centralized participants in this site, which is determined by the number of ties that each participant established in the site (e.g. the ties are represented by the number of lines moving away from or moving towards each participant). Being most centralized means that these preservice teachers have more ties to other preservice teachers in this site and may be in a more advantageous position due to these network connections. Having many ties or connections to other members of the site provides many options to satisfy their questions or requests for information and are less dependent on other individuals. Participants C, F, and D were also very active in this site and established somewhat high number of ties with other participants. The number of connections a person has in a network indicates their prominence or prestige in a given network. Having many ties, these preservice teachers may have access and connections to more of the resources of the network as a whole. Because they have many ties, they are often deal makers or brokers in exchanges among others, and are able to benefit from this brokerage. This analysis shows that the selected students (Participants A-F) established ties with other members of the site and had interactions with a significant number of other participants. 


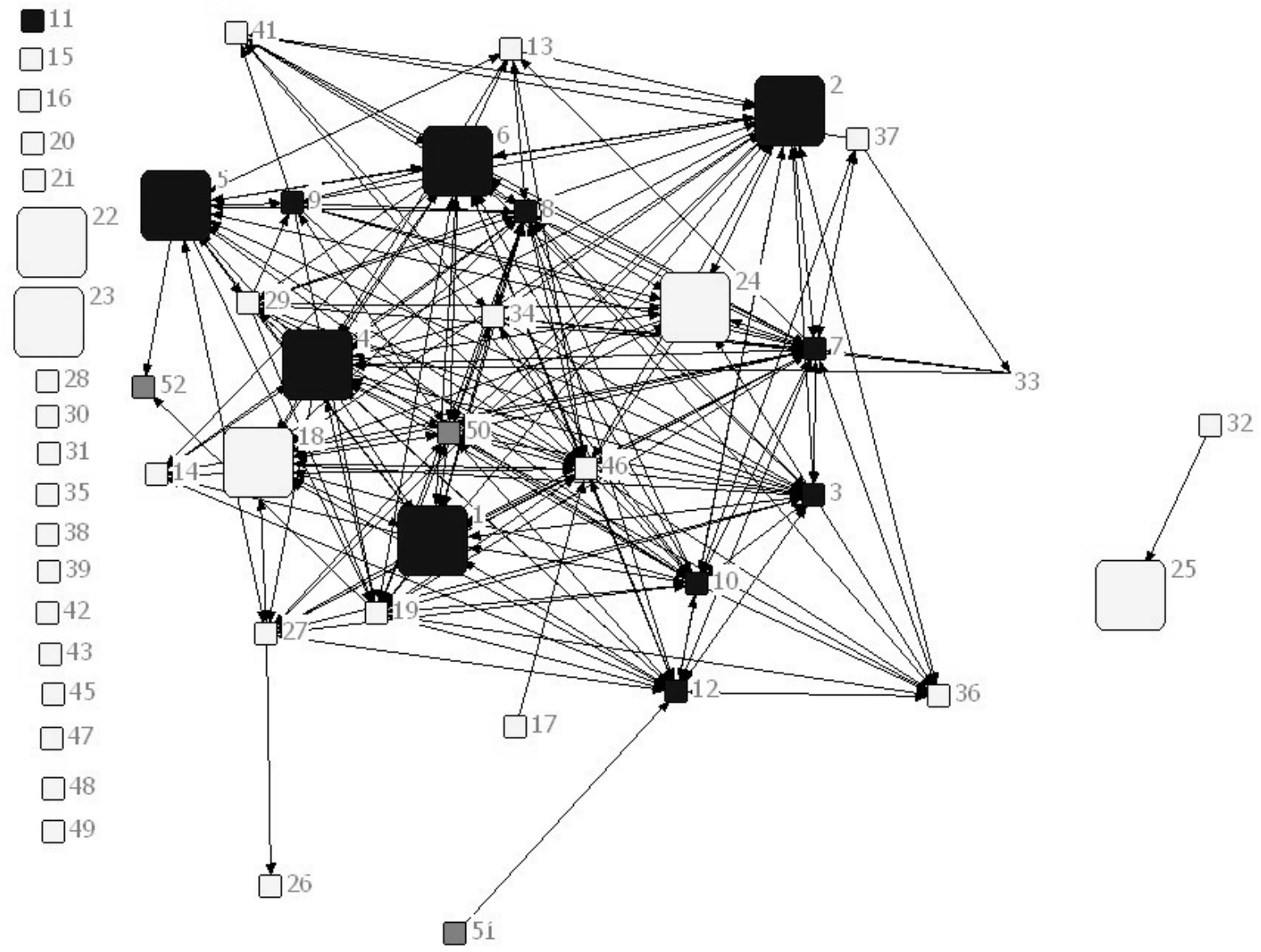

Figure 1. Sociogram of the peer mentoring site. Black represents third-year students. Light grey represents first-year students. Grey represents facilitators. The black lines indicate established ties between actors in this network. Larger nodes indicate that a student has participated in more than one peer mentoring setting.

\section{Discussion}

The present study provided insight into the ways preservice teachers used a peer mentoring site, the social language that developed, and what the online interactions indicated. The results of the CDA revealed that the preservice teachers used the peer mentoring site to engage with one another to continue their learning and development about the various topics of teaching. Additionally, they also used it to share wisdom, stories, experience, and ideas. Moreover, the students sought and gave advice and support, and created mentoring relationships (Glaser at al., 2006).

In addressing the ways the students used the site, the sociogram (see Figure 1) presents the participation of the preservice teachers selected for this study among the entire population of the peer mentoring site, demonstrating a macro-level of the communications. The sociogram allows for the viewing of the selected population and the ability to compare levels of interactions 
of the entire population of the peer mentoring site, not just those selected for this study. The sociogram demonstrates that certain preservice teachers were less active than others in posting comments, questions, and advice. The communications among those who established direct communications were spread across the site, i.e. the students who established direct communications did not focus their posts toward one particular peer. The social network analysis shows that the students communicated across levels with roughly half of the students enrolled being very active in this site. The majority of the students, who established direct connections with other participants shows fairly dense participation levels. These levels indicate that the students were not selective in their advice-seeking or information sharing. Participant D was the only student selected for this study who participated in more than one peer mentoring site, yet she participated the least among the selected participants. The other 5 students selected for this study were new to the peer mentoring site. This is significant because they were all very active participants in this site and influential in driving and carrying conversations. These interactions benefit the learners as Paulin and Haythornthwaite (2016) describe, exposing them to more and different perspectives and integrating them in the education process and provide a view of learning that can influence the design and use of future learning networks (Haythornthwaite, 2013). The first-year students selected for this study were adjusting well to their new online learning environment and taking the initiative to share ideas, ask questions, and interact with one another. With such a high percentage of these students being new to the peer mentoring sites and with previous research showing the many challenges that individuals in new, computersupported learning environments face, including adjustment to new media, new rules of behavior, and new course materials and classmates (Haythornthwaite, 2002), this activity was surprising. The analysis of this activity provides important data regarding the ways in which undergraduate students take or maintain control in an online mentoring site, adding to this body of knowledge (Paulin \& Haythornthwaite, 2016; Rheingold, 2000, 2007).

Regarding social language, the CDA showed that the preservice teachers developed a language of empathy, understanding, and connectedness. Their interactions revealed that they also developed a language of sensitivity toward one another that drove their conversations in the peer mentoring site. Participant B conveyed the anxiousness that first-year preservice teachers exhibited in their posts. Moreover, the interactions provided the students with a system of support to learn, develop, and strengthen their understanding and knowledge of the teaching profession. The students expressed their gratitude for the advice and impact on their development and the strengthening of their confidence to succeed in becoming teachers. These illustrate the findings of Schlager and Fusco (2003) in which communities of practice allowed individuals freedom to think flexibly and experience different forms of support. In engaging with one another, the participants' social interactions provide a context for learning to occur through human understanding and communication, where newcomers can learn from their more experienced peers (Lave \& Wenger, 1991).

The preservice teachers used social language to solve authentic problems in the discussions in this setting as well. Consistent with Barab et al.'s (2002) research among preservice-teacher in a face-to-face preparation program, this research found that participants were not simply learning about the teaching practice (content), but they were also learning about the teaching practice through participating as a community member. These students transformed content and context to an emergent activity that was problematized and open to discussion 
(Barab et al., 2002). Similarly, the students in the peer mentoring site shared and transformed their learning about the practice of teaching as they asked questions of one another and engaged in critical dialogue about relevant topics such as differentiating instruction and classroom management (Meyer, 2006; Nicholson \& Bond, 2013). The stories from their field experiences, roles as parents, and experiences as students were shared with the entire group. One astonishing aspect about their interactions is that the students had never met one another prior to this course. Yet, from their conversations one may conclude that they were friends. As Barab at al. (2002) contend, preservice teachers can design their learning environments to explore their thinking, learn from their peers, and expand, transform, and distribute their learning in their pursuit of teaching.

This study aimed to discover if the peer mentoring site was successful in providing new and more experienced preservice teachers with a forum for interaction to further develop, ask questions, and share what they have learned. The peer mentoring site continues the expansion of online learning and online learning relationships (Haythornthwaite \& Andrews, 2011). The interactions between the preservice teachers uncovered a dynamic process in which the first-year and third-year students engaged with one another to learn from and share their knowledge and experiences with one another with the common goal of becoming successful teachers as the literature on communities of practice suggests (Cross, 1999; Rheingold, 2000, 2007). While all of the preservice teachers we selected participated in the mentoring site, there were a few who did not participate as often as other students. The posts analyzed for this study showed that some students used the site observationally to find answers to their questions - not seeing the need to contribute more to the discussions - such as Participant D who stated, "Most of my questions have been answered by the posts of others."

The CDA of the students' discussion board posts demonstrated that the peer mentoring site was successful in providing new and more experienced preservice teachers with a forum for interaction to further develop, inquire, and share what they have learned. Some of the advice they sought from others centered on the pragmatics of teaching. Participant F's questions about the Praxis exam highlight this point as she searched for additional information regarding the format and preparation for these exams.

In particular, the preservice teachers shared stories from their experiences in schools as student teachers, parents, or employees. They inquired about what methods and practices were proven to be effective in the classroom. These interactions exemplify the learning and social aspects of this site and the ways that the students came together to broaden their thinking and learning. These interactions evoked the findings of Lave and Wenger (1991) in which the participants engage together and develop a way to speak about the enculturation process of becoming a teacher and the activities, identities, and artifacts that are characteristic of their work and field (Lave \& Wenger, 1991). Consistent with the work of Barab and Duffy (2000), the students shared personal narratives and developed a shared language to describe their experiences and practices.

Finally, the study demonstrated that the online peer mentoring site facilitated the cultivation of learning, idea and knowledge exchange of preservice teachers in an innovative learning environment, creating networks of learning as described by Goodyear \& Carvalho 
(2014). The analysis of the participants' Discussion Board posts illuminated how the participants used the peer mentoring site and the social language that was developed between the first- and third-year preservice teachers in which they discussed critical issues in the field of education, raised questions about teaching practices, and developed important relationships with other students on the site. Both first-year and third-year students were very active in asking questions and participating in the peer mentoring site. Their interactions demonstrated the powerful influence peers can have on students entering higher education (Ender \& Newton, 2000). While most research studies on peer mentoring have focused on face-to-face settings (Dennen, 2004), this research presents the benefits of an online site by providing preservice teachers a place where informal learning and social around issues of teaching and praxis can occur. This research also demonstrates the heightened reflective experiences that mentors and mentees can have in computer-supported collaborative settings (Hayward et al., 2000), like this peer mentoring site.

\section{Recommendations}

Facilitating interaction among the students was one of the established goals for the peer mentoring site (Haythornthwaite, 2002). While the facilitator was not a focus of this study, future studies can address the role of the facilitator and make recommendations for his/her role. These recommendations can include whether the facilitator(s) should actively reach out to engage students who may be outliers to increase student participation and the role of incentives for students, e.g. points for participation, among others. Such research can provide insight into what motivates some students to participate more than others. Future research about the site from the students' perspectives would be beneficial in gaining further insight into their communication patterns. This insight would also inform ways that the site can improve to better meet students' needs.

This study also provides a foundation for future analysis of specially designed peer mentoring settings and identification of patterns within such settings. With the limited research available regarding mentoring and communities of practice in online settings, analysis of the student interactions in such settings provides a foundation upon which future research can build. One limitation is that the six (6) students we focused on in this paper were all female. The preservice teachers selected for this study being all female in gender was a product of the course registration process and not of the purposeful sampling method. While this was not purposeful and represented the demographics of most students enrolled in the peer mentoring site, this could still be viewed as a limitation. Another limitation was our decision to limit our analysis using the CDA to six (6) representative students from the site instead of analyzing the discussion data of a larger number of participants. A final limitation is that all of the students were nontraditional students returning to college after a hiatus. With the expectation that these students have different needs and experiences than traditional full-time students, further research can explore the ways specific student populations use an online peer mentoring site. For instance, do nontraditional adult learners use the site in different ways than students who transitioned directly from high school? Additionally, research regarding the relationship patterns of individual preservice teachers participating in online peer mentoring settings would provide additional insight into the networks that participants had formed. 
Analysis of Discussion Board Interaction in an Online Peer Mentoring Site

\section{References}

Barab, S. (2003). An Introduction to the Special Issue: Designing for Virtual Communities in the Service of Learning. Information Society, 19(3), 197-201.

Barab, S. A., Barnett, M. G., \& Squire, K. (2002). Building a community of teachers: Navigating the essential tensions in practice. The Journal of the Learning Sciences, 11(4), 489-542.

Barab, S. A. \& Duffy, T. (2000). From practice fields to communities of practice. In D. Jonassen \& S. M. Land. (Eds.), Theoretical foundations of learning environments (pp. 25-56). Mahwah, NJ: Lawrence Erlbaum Associates.

Benkler, Y. (2006). The wealth of networks: How social production transforms markets and freedom. Yale University Press.

Borgatti, S. P., Everett, M. G. \& Freeman, L. C. 2002. UCINET for Windows: Software for Social Network Analysis. Harvard, MA: Analytic Technologies.

Cross, K. P. (1999). Assessment to improve college instruction. In S. J. Messick (Ed.), Assessment in higher education: Issues of access, quality, student development, and public policy (pp. 35-46). Mahwah, NJ: Erlbaum.

Dennen, V.P. (2004). Cognitive apprenticeship in educational practice: Research on scaffolding, modeling, mentoring, and coaching as instructional strategies. In D. H. Jonassen (Ed.) Handbook of research for educational Communications and technology: a project of the association for educational communications and technology (pp 813-828). New York: Macmillan.

Ender, S. C., \& Newton, F. B. (2000). Students helping students: A guide for peer educators on college campuses. Health Education Research, 17, 339-349.

Feenberg, A. \& Bakardjieva, M. (2004). Virtual community: No ‘killer implication’. New Media and Society, 6(1), 37-43.

Gee, J. (1989). Literacy, discourse, and linguistics: Introduction. Journal of Education, 171, 5-17.

Gee, J. (2001). Reading as situated language: A sociocognitive perspective. Journal of Adolescent and Adult Literacy, 44(8), 714-25.

Gee, J. (2005). An introduction to discourse analysis: Theory and method. New York: Routledge.

Gee, J. (2011). Discourse analysis: What makes it critical? In R. Rogers (Ed.), An Introduction to critical discourse analysis in education ( $2^{\text {nd }}$ Ed.) (pp. 23-45). New York: Routledge.

Glaser, N., Hall, R., \& Halperin, S. (2006). Students supporting students: The effects 
Analysis of Discussion Board Interaction in an Online Peer Mentoring Site

of peer mentoring on the experiences of first year university students. Journal of the Australia and New Zealand Student Services Association, 27, 4-19.

Goodyear, P. \& Carvalho, L. (2014). The Architecture of Productive Learning Networks. New York: Routledge.

Haythornthwaite, C. (2002). Building social networks via computer networks: Creating and sustaining distributed learning communities. In Renninger, K. A. \& Shumar, W. (Eds.), Building virtual communities (pp. 159-190). Cambridge: Cambridge University Press.

Haythornthwaite, C. (2005). Social networks and Internet connectivity effects. Information, Community \& Society, 8(2), 125-147.

Haythornthwaite, C. \& Andrews, R. (2011). E-learning theory and practice. London: Sage.

Haythornthwaite, C. (2012) New Media, New Literacies, and New Forms of Learning. International Journal of Learning and Media 2012 4:3-4, 18. http://www.mitpressjournals.org/doi/abs/10.1162/IJLM_e_00097

Haythornthwaite, C. (2013). Emergent practices for literacy, e-learners, and the digital university. In R. Goodfellow \& M. Lea (eds). Literacy in the Digital University (pp. 56- 66). Routledge.

Hayward, L. M., DiMarco, R., Blackmer, B., Canali, A., Wong, K., \& O’Brien, M. (2001). Curriculum-based electronic peer mentoring: an instructional strategy for integrative learning. Journal Physical Therapy Education, 15(4), 14-25.

Lave, J., \& Wenger, E. (1991). Situated learning: Legitimate peripheral participation. Cambridge: Cambridge University Press.

Marin, A., \& Wellman, B. (2010). Social Network analysis: An Introduction. In Peter Carrington and John Scott (Eds.), Handbook of Social Network Analysis. London: Sage.

Meyer, K. (2006). The method and madness of evaluating online discussions. Journal of Asynchronous Learning Networks, 10, 83-97.

Nicholson, S.A. \& Bond, N. (2003). Collaborative reflection and professional community building: An analysis of preservice teachers' use of an electronic discussion board. Journal of Technology and Teacher Education, 11(2), 259-279.

Paulin, D. \& Haythornthwaite, C. (2016). Crowdsourcing the curriculum: Redefining e-learning practices through peer-generated approaches. The Information Society, 32(2), 130-142.

Rainie, H., \& Wellman, B. (2012). Networked: The new social operating system (p. 358). Cambridge, MA: MIT Press. 
Analysis of Discussion Board Interaction in an Online Peer Mentoring Site

Rheingold, H. (2000). The virtual community: Homesteading on the electronic frontier. MIT press.

Rheingold, H. (2007). Smart mobs: The next social revolution. Basic books.

Romiszowski, A. J. and Ravitz, J. (1997). Computer-mediated communication. In C. R. Dilles \& A. Romiszowski (Eds.), Instructional developmental paradigm (pp. 745-768). Englewood Cliffs, NJ: Educational Technology Publications.

Rogers, R. (Ed.). (2011). An introduction to critical discourse in education. New York: Routledge.

Rogoff, B., Baker-Sennett, J., Lacasa, P., \& Goldsmith, D. (1995). Development through participation in sociocultural activity. Cultural Practices as Contexts for Development, 67, 45-65.

Ruane, R. (2012). A study of student interaction in an online learning environment specially crafted for cross-level peer mentoring (Doctoral Dissertation). Available from ProQuest Dissertations and Theses database. (UMI No. 353369)

Scheckler, R. K. \& Barab, S. A. (2009). Designing for inquiry as a social practice. In Falk, J. \& Drayton, B. (Eds.), Creating and sustaining online professional communities (pp. 125-152). New York: Teachers College Press.

Schlager, M. S., \& Fusco, J. (2003). Teacher professional development, technology, and communities of practice: Are we putting the cart before the horse? The Information Society, 19, 203. doi: 10.1080/01972240390210046

Scott, J., \& Carrington, P. J. (2011). The SAGE handbook of social network analysis. SAGE publications.

Sfard, A. (2008). Thinking as communication. Cambridge: Cambridge University Press.

Stahl, G., Koschmann, T., \& Suthers, D. (2013). Computer-supported collaborative learning: An historical perspective. In R. K. Sawyer (Ed.), Cambridge handbook of the learning sciences, revised version. Cambridge, UK: Cambridge University Press.

Wellman, B. (1997). An electronic group is virtually a social network. Culture of the Internet, 4, 179-205.

Winebrenner, S. (2000). Gifted students need an education, too. Educational leadership, 58(1), 52-56. 